\title{
PENGARUH INOVASI SOSIAL“LOCAL BUSINESS DEVELOPMENT” DENGAN STRATEGI BUSINESS MODEL CANVA (BMC) TERHADAP MODEL BISNIS UMKM PROGRAM CSR PESONA WALAHAR CREATIVE DESTINANTION BINAAN PT PERTAMINA (Persero) FUEL TERMINAL CIKAMPEK
}

\section{THE EFFECT OF SOCIAL INNOVATION "LOCAL BUSINESS DEVELOPMENT" \\ WITH THE BUSINESS MODELS CANVA STRATEGY ON BUSINESS MODELS \\ UMKM CSR PROGRAM PESONA WALAHAR CREATIVE DESTINATION FOUND PT PERTAMINA (Persero) FUEL TERMINAL CIKAMPEK}

\author{
Taufik Ismail ${ }^{1}$, Reza Rinaldy ${ }^{1}$, Mezy Fadhila ${ }^{1}$, Nuril Endi Rahman ${ }^{2 *}$ \\ ${ }^{1}$ Pertamina (Persero) Fuel Terminal Cikampek \\ ${ }^{2}$ Universitas Muhammadiyah Madiun \\ Jl. Achmad Yani Km 6, Dawuan Barat, Cikampek, Karawang ,Jawa Barat \\ Jl. Mayjen Panjaitan No. 18, Banjarrejo, Madiun, Jawa Timur \\ *Email: nuril.endy@gmail.com \\ (Diterima 03-09-2021; Disetujui 24-09-2021)
}

\begin{abstract}
ABSTRAK
Pada tahun 2021 Pesona Walahar akan melakukan pembangunan kawasan ekonomi kreatif dan terintegrasi melalui kearifan lokal. Pengelolaan integrasi antara wisata, UMKM, dan usaha ekonomi kreatif dijadikan sebagai daya tarik dan pembangkit ekonomi masyarakat demi mengusung desa wisata serta melakukan penerapan CHSE di sekitar bendungan Walahar. Untuk mewujudkan hal tersebut diperlukan data kondisi model bisnis UMKM dan para pelaku ekonomi kreatif di wilayah Desa Walahar untuk dijadikan acuan. Data kondisi awal ini akan menangkap data tentang bagaimana perjalanan para pelaku UMKM dan ekonomi kreatif di Desa Walahar bertahan pada masa sulit pandemi Covid-19. Penelitian menggunakan metode kualitatif dengan pendekatan indepth interview dan Focus Group Discussion (FGD) yang hasilnya diperlukan sebagai bahan pertimbangan pembuatan model pengembangan bisnis yang sesuai dengan kondisi dan potensi sosial ekonomi masyarakat. Peneliti melakukan pengumpulan data kondisi model bisnis sederhana para pelaku UMKM dan ekonomi kreatif di Desa Walahar menggunakan teknik wawancara mendalam untuk menangkap kondisi nyata dan strategi informan dalam membangun bisnis dan bertahan di masa pandemi Covid-19. Hasilnya, inovasi sosial yang dilakukan oleh tim CSR PT Pertamina (Persero) Fuel Terminal Cikampek dengan titik ungkit pemberdayaan melalui Yasayan Pesona Walahar Kreatif memunculkan sifat kolaboratif, saling mendukung promosi produk yang dimiliki penerima pelaku usaha lain, serta saling bahu membahu di kalangan para penerima manfaat untuk terus bertahan menjalankan usahanya. Kedepannya, Yayasan Pesona Walahar Kreatif dan para penerima manfaatnya perlu membangun kerjasama dengan para pemangku kepentingan untuk akselerasi kebaruan ilmu pengetahuan dan model bisnis, pengembangan strategi pemasaran dan produksi berkelanjutan, serta akselerasi pemasaran yang dilakukan secara paralel agar tidak tergerus di era disrupsi dan pandemi Covid-19.
\end{abstract}

Kata Kunci: Pesona Walahar Kreatif, Kolaborasi, UMKM, Era Disrupsi Covid-19

\section{ABSTRACT}

In 2021 Pesona Walahar Will develop a creative and integrated economic area through local wisdom management of integration between tourism, UMKM, and creative economy business is use as an attraction and economic generator for the community in order to promote tourism villages and implement CHSE arround the Walahar DAM. To achieve this, data on the condition of the UMKM business model and creative economy actors in the Walahar village area are needed to be used as a reference. This initial condition data will capture data on how the journey of UMKM and the creative economy actors in Walahar village survived during the difficult time of the Covid-19 Pandemic. This reseacrh uses a qualitative method with an in-depht interview an Focus Grup Discussion (FGD) approach, the result of which are needed as a consideration for making a business development model that is in accordance with the socio-economic conditions and potential of the community. Researcher collect data on the condition of simple business model for the UMKM and creative economy actors in Walahar village using in-depht interview techniques to capture real condition and informants strategies in building a business and surviving the Covid-19 pandemic. As a result, social innovation carried out by the CSR team of PT Pertamina (Persero) Fuel Terminal 
Pengaruh Inovasi Sosial "Local Business Development" dengan Strategi Business Model Canva (BMC) Terhadap Model Bisnis UMKM Program CSR Pesona Walahar Creative Destinantion Binaan PT. Pertamina (Persero) Fuel Terminal Cikampek

Taufik Ismail, Reza Rinaldy, Mezy Fadhila, Nuril Endi Rahman

Cikampek with a lever of empowerment through Pesona Walahar Kreatif Foundation have created a collaborative nature, mutually support the promotion of product owned by recipients of other business actors, and team work among benneficaries to continue their business. In the future, Pesona Walahar Kreatif Foundation and its benneficiaries need to build cooperation with stakeholders to accelerate scientific novelty and business models, develop marketing strategies and sustainable production, as well as accelerate marketing carried out in pararel so as not to be affected in disruption era and Covid-19 Pandemic.

Keyword: Pesona Walahar Kreatif, Collaboration, UMKM, Disruption era and Covid-19

\section{PENDAHULUAN}

PT Pertamina (Persero) Fuel Terminal Cikampek melalui program CSR dengan metode pemberdayaan masyarakat memiliki komitmen yang kuat di wilayah Desa Walahar, Kecamatan Klari, Kabupaten Karawang. Desa Walahar merupakan desa yang termasuk dalam ring 1 perusahaan. Sejak tahun 2020 program pemberdayaan masyarakat dilaksanakan dengan mengembangkan program yang melihat potensi sumber daya manusia dan alam yang dimiliki Desa Walahar. Adapun Desa Walahar dicanangkan akan menjadi desa wisata dengan menggandeng produk-produk dengan kearifan lokal, membantu mengembangkan ekonomi kreatif masyarakat serta membangkitkan peran UMKM dan kelompok sadar wisata di Desa Walahar dengan ikon Bendungan Walahar.

Pada tahun 2021 Pesona Walahar akan melakukan pembangunan kawasan ekonomi kreatif dan terintegrasi melalui kearifan lokal. Pengelolaan integrasi antara wisata, UMKM, dan usaha ekonomi kreatif dijadikan sebagai daya tarik dan pembangkit ekonomi masyarakat demi mengusung desa wisata serta melakukan penerapan CHSE di sekitar bendungan Walahar. Pembangunan kawasan ekonomi kreatif ini bekerjasama dengan berbagai pemangku kepentingan yang terlibat sehingga menciptakan konsep "The Great Wonderful Walahar". Untuk mewujudkan hal tersebut diperlukan data kondisi model bisnis UMKM dan para pelaku ekonomi kreatif di wilayah Desa Walahar untuk dijadikan acuan. Pendataan kondisi awal ini akan menangkap data tentang bagaimana perjalanan para pelaku UMKM dan ekonomi kreatif di Desa Walahar. Hasil pemetaan ini diperlukan sebagai bahan pertimbangan pembuatan model pengembangan bisnis yang sesuai dengan kondisi dan potensi sosial ekonomi masyarakat. Data lain yang diambil adalah pemetaan potensi dan kebutuhan pemangku kepentingan pentahelix (akademisi, bisnis, komunitas, pemerintah, dan media) yang dapat mendukung akselerasi pengembangan program bagi para pelaku UMKM binaan PT Pertamina (Persero) Fuel Terminal Cikampek. Hasil kegiatan ini diharapkan juga dapat dijadikan acuan program dan kebijakan pengembangan daerah kawasan ekonomi kreatif bendungan Walahar. 


\section{BAHAN DAN METODE}

Metode yang digunakan dalam penelitian ini adalah metode kualitatif dengan pendekatan indepth interview dan Focus Group Discussion (FGD). Tim melakukan pengumpulan data kondisi model bisnis sederhana para pelaku UMKM dan ekonomi kreatif di Desa Walahar menggunakan teknik wawancara mendalam untuk menangkap kondisi nyata dan strategi informan dalam membangun bisnis dan bertahan di masa pandemi Covid-19. Wawancara mendalam dilaksanakan dengan mendatangi langsung ke 5 (lima) simpul-simpul utama UMKM dan para pelaku ekonomi kreatif di Desa Walahar. Tidak hanya wawancara mendalam, tujuan lain mendatangi tempat informan adalah untuk mengobservasi kegiatan sehari-hari, bisnis, dan usaha kreatif mereka. Teknik ini sangat cocok diterapkan untuk pengumpulan data di Desa Walahar karena sejalan dengan kondisi sosial budaya masyarakat yang lebih terbuka dengan obrolan secara langsung. Beberapa kelompok pertanyaan yang disampaikan pada para informan adalah sebagai berikut:

Kelompok Pertanyaan 1: Bagaimana gambaran umum usaha Anda?

Kelompok Pertanyaan 2: Value apa yang ditawarkan produk Anda pada customer?

Kelompok Pertanyaan 3: Segmentasi konsumen seperti apa yang dituju oleh bisnis Anda?

Kelompok Pertanyaan 4: Siapa saja partner bisnis Anda?

$\square$ Akademisi

$\square$ Bisnis

$\square$ Komunitas

$\square$ Pemerintah

$\square$ Media

Kelompok Pertanyaan 5: Dari kegiatan apa saja bisnis Anda mendapatkan saluran pendapatan?

Pendekatan FGD dilakukan untuk pengumpulan data kondisi dan kebutuhan pemangku kepentingan yang ada di Desa Walahar. FGD dihadiri oleh 8 (delapan) orang peserta yang berasal dari tokoh pemuda, karang taruna, kelompok kreatif, dan perangkat desa. Kegiatan FGD diselenggarakan di ruang-ruang kolaboratif yang biasa dijadikan titik berkumpul para tokoh peserta FGD.

\section{HASIL DAN PEMBAHASAN}

PT Pertamina (Persero) Fuel Terminal Cikampek dalam hal ini pihak bisnis memberikan program CSR kepada Desa Walahar berupa bantuan sarana prasarana serta berbagai program pengembangan masyarakat yang disalurkan melalui Yayasan Pesona 
Pengaruh Inovasi Sosial "Local Business Development" dengan Strategi Business Model Canva (BMC) Terhadap Model Bisnis UMKM Program CSR Pesona Walahar Creative Destinantion Binaan PT. Pertamina (Persero) Fuel Terminal Cikampek

Taufik Ismail, Reza Rinaldy, Mezy Fadhila, Nuril Endi Rahman

Walahar Kreatif. Penyaluran bantuan yang dilakukan oleh Yayasan Pesona Walahar Kreatif disesuaikan berdasarkan kebutuhan kelompok UMKM dan para pelaku ekonomi kreatif yang telah dipetakan sebelumnya. Yayasan ini dibuat dengan bantuan bimbingan dari PT Pertamina (Persero) Fuel Terminal Cikampek untuk melakukan aktivitas pemberdayaan masyarakat dengan menggandeng UMKM dan para pelaku ekonomi kreatif sebagai penerima manfaatnya. Berikut adalah profil singkat para penerima manfaat dari Yayasan Pesona Walahar Kreatif:

1. Kelompok Kopi Parisdo

\section{The Business Model Canvas Kelompok Kopi Parisdo}

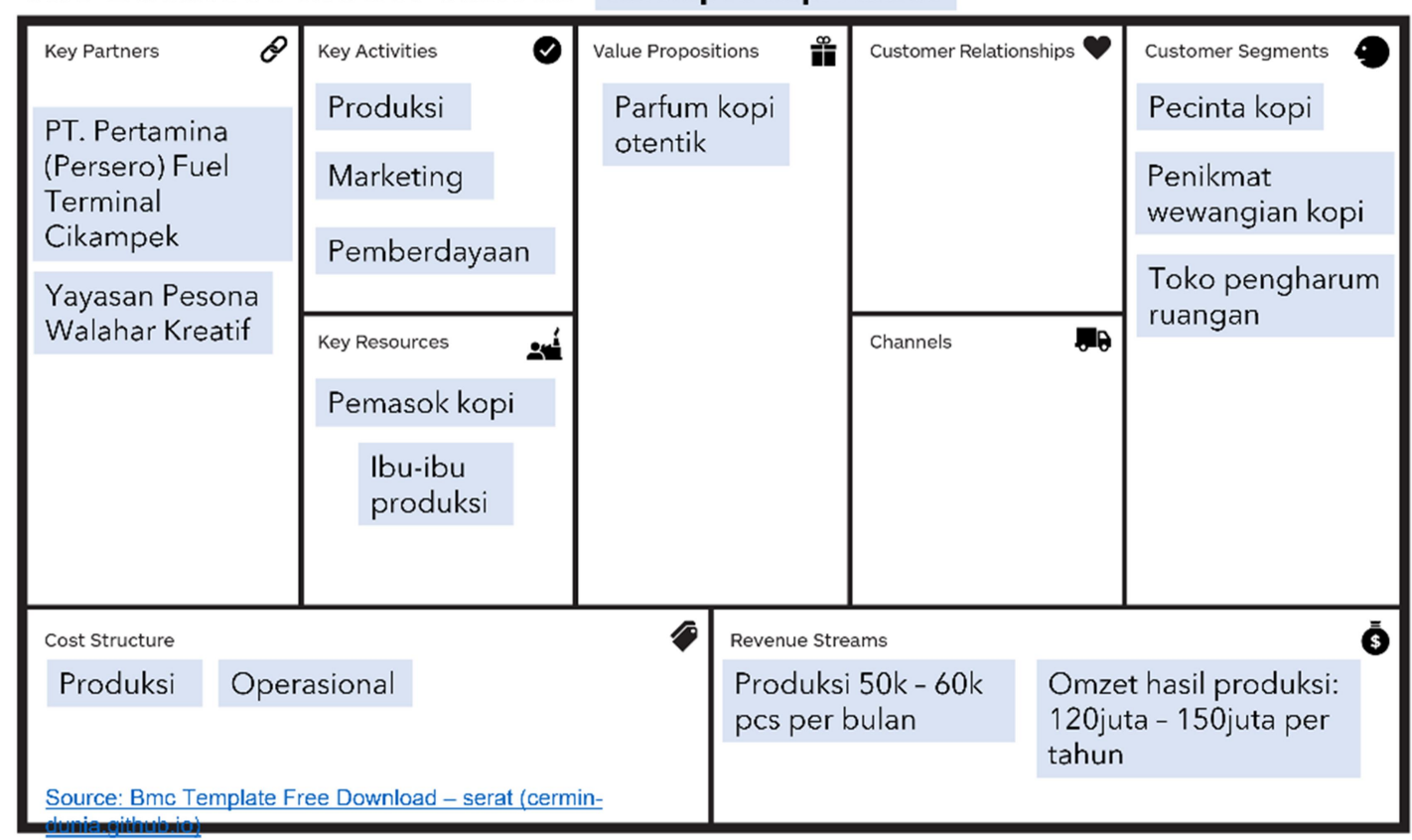

Kelompok Kopi Parisdo merupakan kelompok usaha yang bergerak di bidang pengolahan kopi menjadi kopi pengharum, baik kopi pengharum ruangan, kendaraan, dan parfum. Bisnis ini memiliki tenaga kerja 15-20 orang dengan memberdayakan perempuan/ibu-ibu sekitar untuk menambah pemasukan ekonomi keluarga, dengan kapasitas produksi sebesar 50.000-60.000 Pieces kopi pengharum per bulan dengan omzet pasca terkena dampak ekonomi selama pandemi covid-19 sekitar Rp 120.000.000 sampai dengan $\mathrm{Rp} 150.000 .000$ per tahun. 
2. Kelompok Kopi Lingga

\section{The Business Model Canvas Kelompok Kopi Lingga}

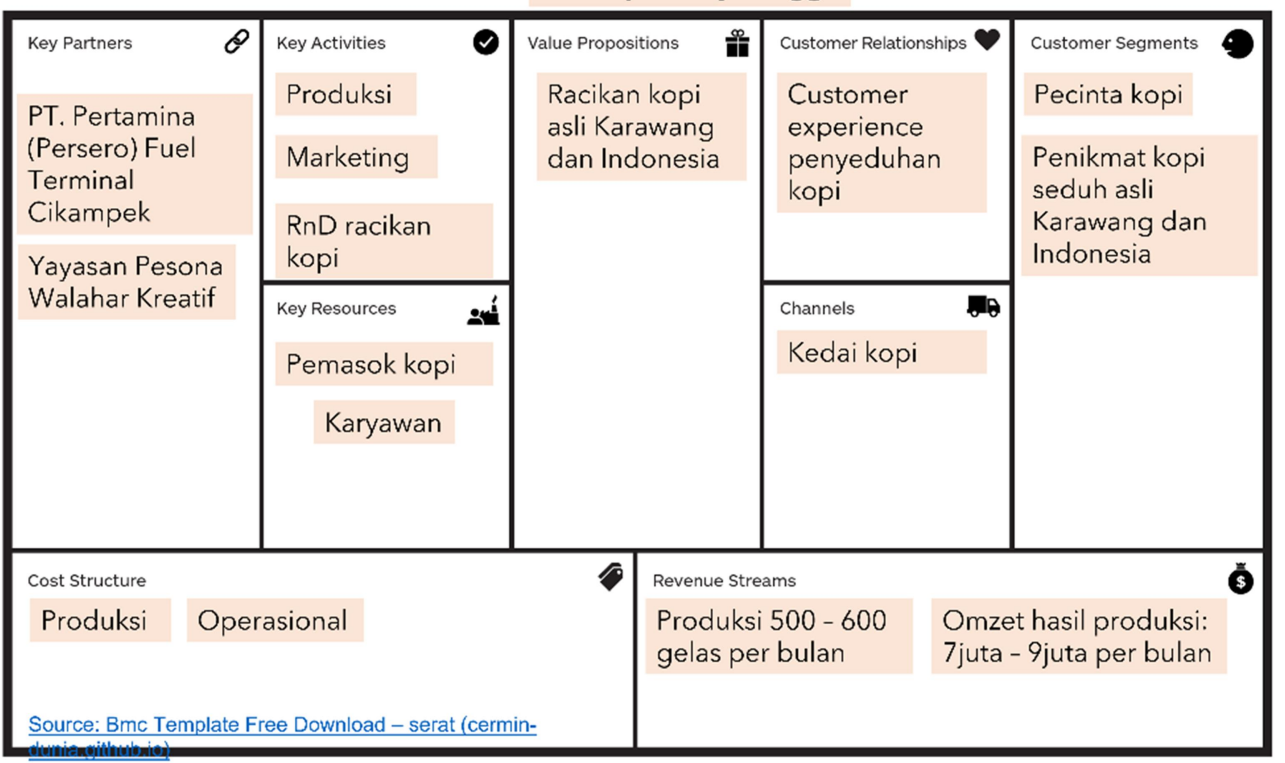

Kelompok Kopi Lingga adalah kelompok usaha di bidang usaha kedai kopi yang melakukan layanan penyediaan kopi seduh melalui biji asli kopi Indonesia dan Karawang. Kelompok usaha Kopi Lingga memiliki 3-5 orang karyawan yang membantu usahanya tetap bertahan dengan kapasitas produksi harian mencapai 500-600 gelas per bulan dengan omzet pasca terkena dampak ekonomi selama pandemi covid-19 menjadi $\mathrm{Rp} 7.000 .000$ sampai dengan Rp 9.000.000 per bulan.

3. Kelompok Ukir Kayu

\section{The Business Model Canvas Kelompok Ukir Kayu}

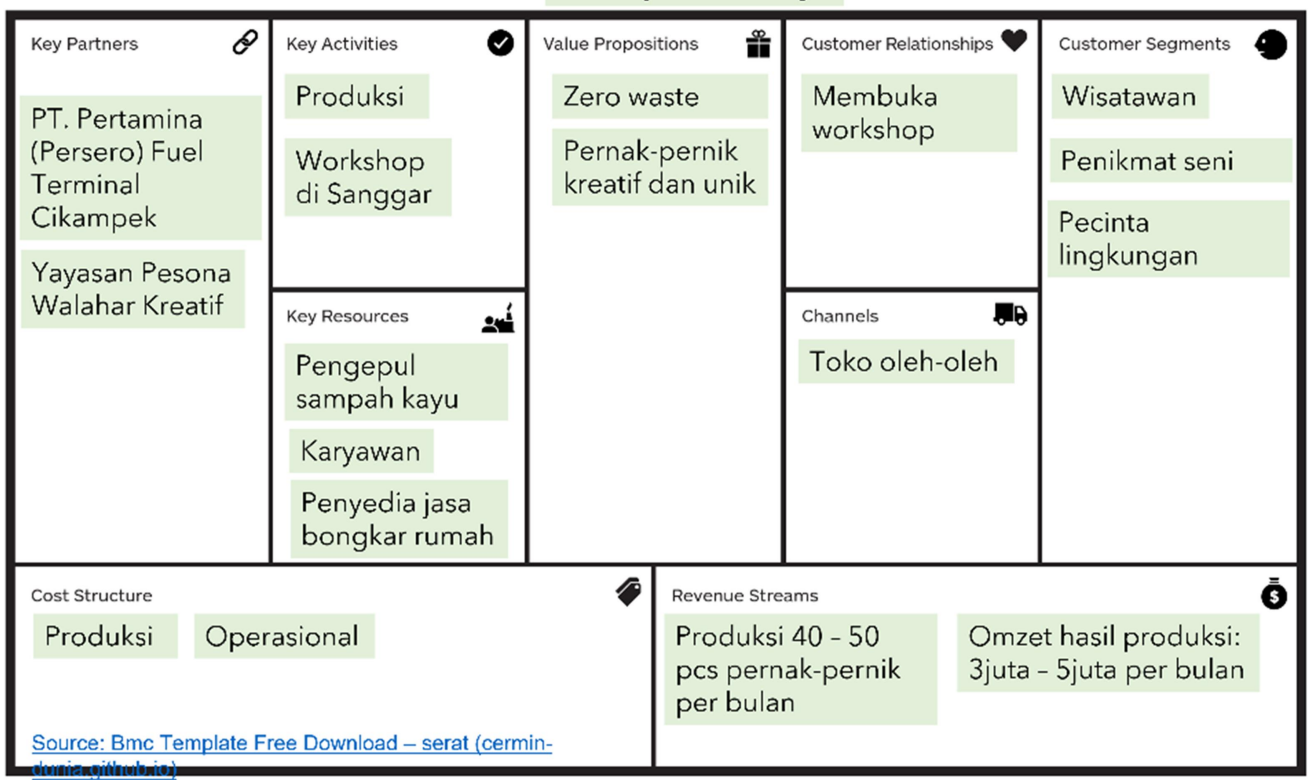

Kelompok Ukir Kayu merupakan kelompok pengrajin hasil olahan kayu menjadi barang-barang unik dan kreatif, bisa berbentuk barang tepat guna atau barang hiasan 
Pengaruh Inovasi Sosial "Local Business Development" dengan Strategi Business Model Canva (BMC) Terhadap Model Bisnis UMKM Program CSR Pesona Walahar Creative Destinantion Binaan PT. Pertamina (Persero) Fuel Terminal Cikampek

Taufik Ismail, Reza Rinaldy, Mezy Fadhila, Nuril Endi Rahman

semata yang dihasilkan dari limbah kayu jati atau kayu yang tidak terpakai bekas pembongkaran rumah atau bangunan yang menjadi limbah. Pengembangan channeling pemasaran yang selama ini dilakukan adalah dengan menyasar ke toko oleh-oleh yang ada di Desa Walahar dan Karawang. Cara mereka membangun hubungan dengan konsumen selain dari penjualan adalah dengan membuka tempat workshop bagi siapa saja yang tertarik mempelajari ukiran dari limbah kayu menjadi kerajinan berilai tambah. Proses pengolahan limbah kayu menjadi hasil kerajinan tangan yang unik ini mampu menyerap 46 orang tenaga kerja dan membimbing 10-15 anak yang belajar di sanggar ukir kayu. Dengan jumlah tenaga kerja yang ada, Kelompok Ukir Kayu mampu menghasilkan produksi aneka kerajinan tangan sebanyak 40-50 produk setiap bulan dengan omzet pasca terkena dampak ekonomi selama pandemi covid-19 sekitar Rp 3.000.000 sampai dengan Rp 5.000.000 juta per bulan.

4. Kelompok Jam Kayu

\section{The Business Model Canvas Kelompok Jam Kayu}

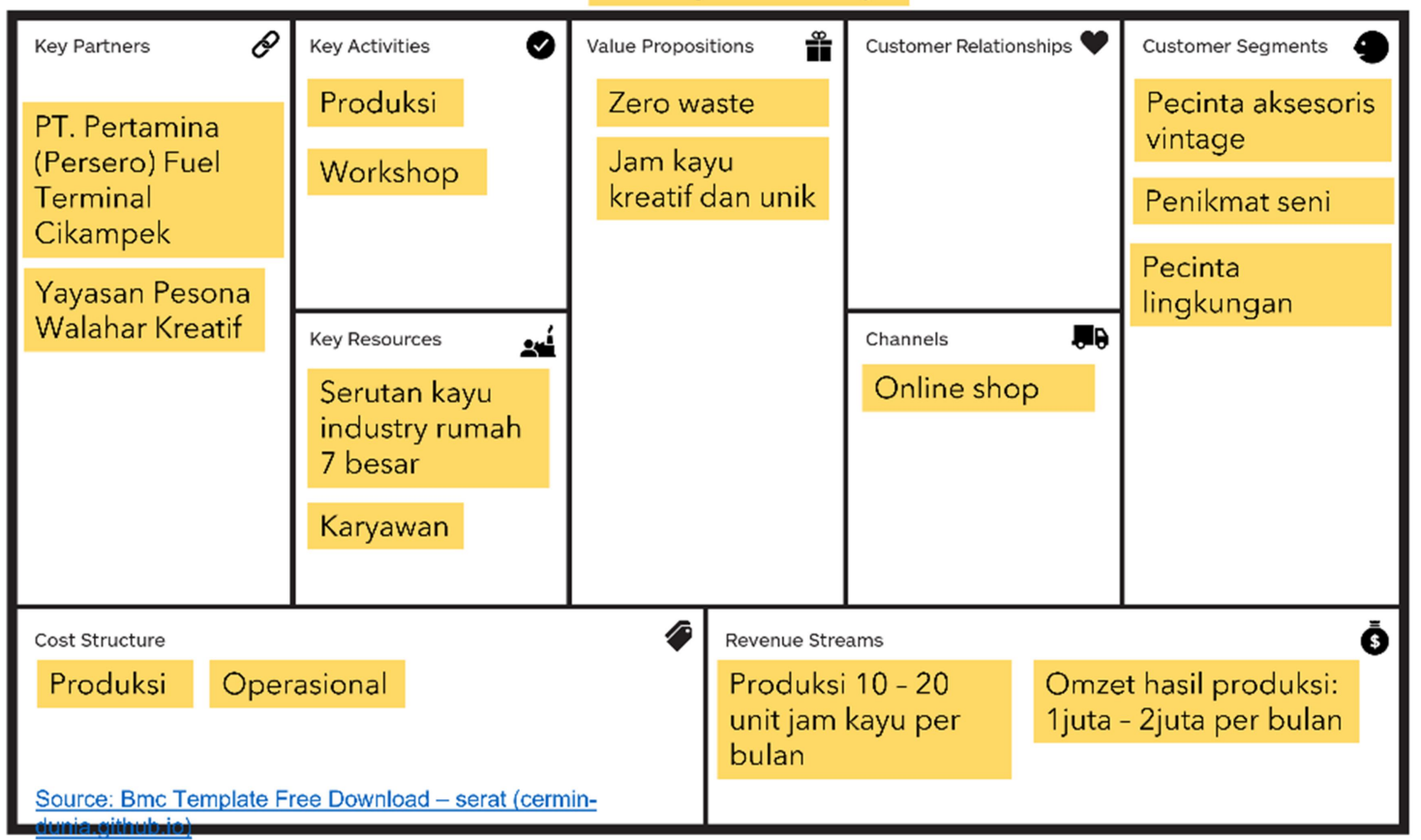

Kelompok Jam Kayu merupakan kelompok pengrajin yang membuat jam dinding dengan bahan limbah serutan kayu dari industri rumahan atau industri besar. Kelompok pengrajin ini menyasar pasarnya menggunakan media penjualan dalam jaringan. Dengan model bisnis yang saat ini dijalankan mereka mampu menyerap tenaga kerja sebanyak 2-3 orang dan menghasilkan produk kerajinan tangan sebanyak 10 sampai 20 unit jam kayu setiap bulannya dengan omzet pasca terkena dampak ekonomi selama pandemi covid-19 menjadi sekitar Rp 1.000.000 sampai dengan Rp 2.000.000 per bulan. 
5. Kelompok Walahar Kreatif

The Business Model Canvas Kelompok Walahar Kreatif

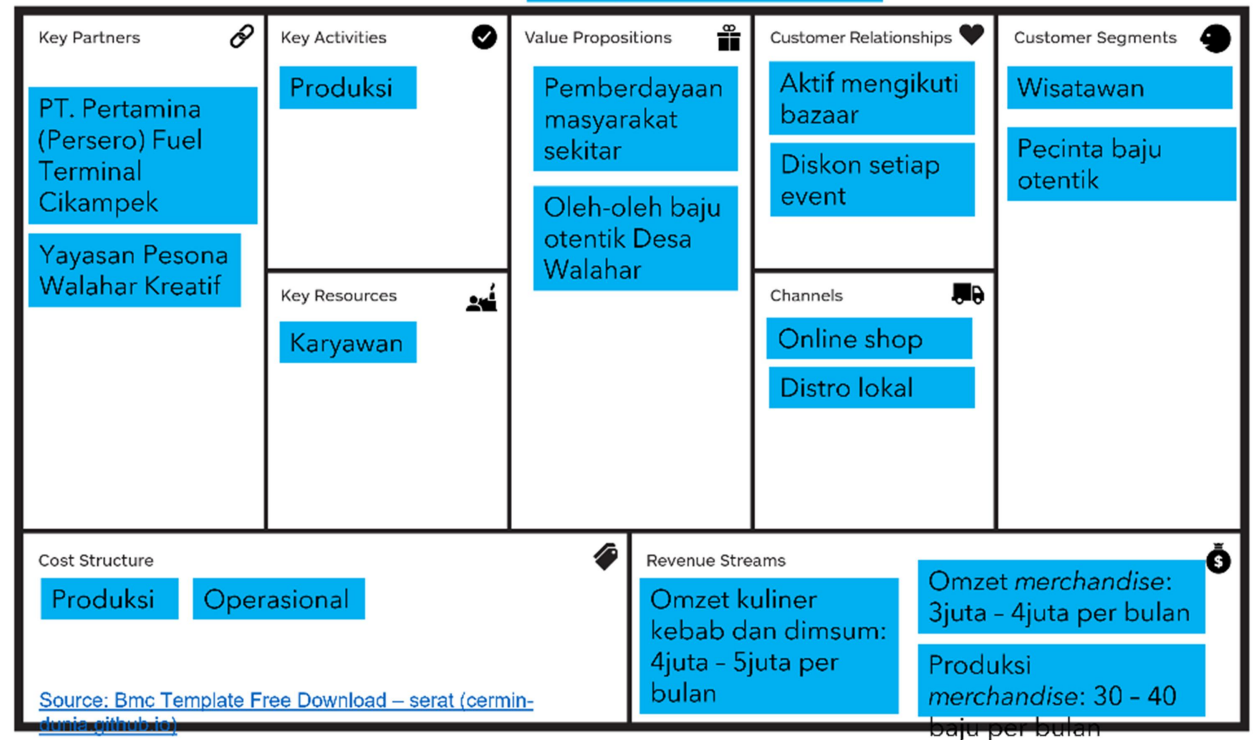

Kelompok yang terdiri atas 8 orang yang memiliki bidang usaha kuliner dan merchandise serta menjadi koordinator dari kelompok UMKM di Walahar, dengan memberikan manfaat kepada 10-12 orang dalam bidang usahanya. Di bidang kuliner Kelompok Walahar Creative memiliki usaha Kebab dan Dimsum dengan omzet penghasilan pasca terkena dampak ekonomi selama pandemi Covid-19 sebanyak Rp 4.000.000 sampai dengan Rp 5.000.000 per bulan dan merchandise berupa baju sebagai oleh-oleh khas Walahar dengan penjualan 30-40 baju per bulan dengan omzet sekitar Rp 3.000.000 sampai dengan Rp 4.000.000 per bulan.

6. Kelompok Eceng Gondok

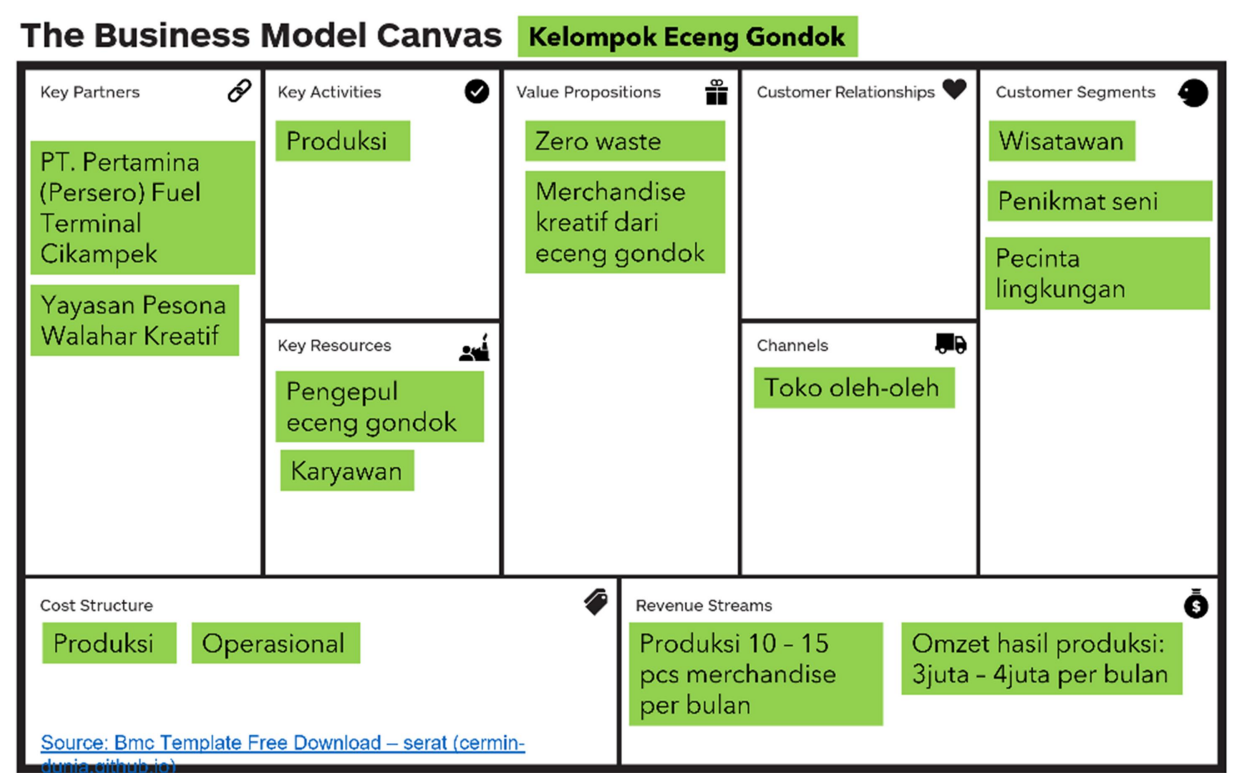


Pengaruh Inovasi Sosial "Local Business Development" dengan Strategi Business Model Canva (BMC) Terhadap Model Bisnis UMKM Program CSR Pesona Walahar Creative Destinantion Binaan PT. Pertamina (Persero) Fuel Terminal Cikampek

Taufik Ismail, Reza Rinaldy, Mezy Fadhila, Nuril Endi Rahman

Kelompok yang terdiri atas 4-8 orang yang memiliki bidang usaha kerajinan tangan berupa pembuatan tas, kursi, meja, topi dan lain-lain dari pemanfaatan limbah eceng gondok menjadi barang yang bernilai ekonomis, produk yang mampu dihasilkan setiap bulan berkisar 10-15 produk dengan omzet sekitar Rp 3.000.000 sampai dengan Rp 4.000.000 per bulan, mampu mengolah limbah 300-400 kg eceng gondok tangkai dan 30$40 \mathrm{~kg}$ eceng gondok kering dalam membuat produk setiap bulannya.

Pandemi Covid-19 memberikan dampak yang cukup signifikan pada para penerima manfaat Yayasan Pesona Walahar Kreatif. Penurunan nilai omzet sebelum dan pasca pandemi Covid-19 melanda mencapai 30\% sampai 50\%. Penurunan permintaan dari luar Karawang menurunkan target produksi bulanan. Saat ini para kelompok UMKM dan para pelaku ekonomi kreatif binaan Yayasan Pesona Walahar Kreatif fokus mengandalkan pemasaran di tingkat lokal, yaitu Karawang.

Di sisi lain, dampak ekonomi ternyata membuat Yayasan Pesona Walahar Kreatif dan para penerima manfaat lebih erat dalam berkolaborasi, saling promosi produk yang dimiliki oleh penerima manfaat yang lain, serta saling bahu-membahu untuk terus bertahan menjalankan usahanya. Media sosial dan jejaring forum bisnis masih menjadi media yang dijadikan untuk menjaga hubungan mereka dengan pelanggan. Target market yang dituju cukup beragam, ada yang menyasar business to business, ada juga yang fokus kepada business to customer, dalam hal ini yang konsisten dapat diterima oleh toko adalah Kelompok Kopi Parisdo. Selain itu, ada juga mitra kunci yang turut membantu keberlangsungan usaha mereka diantaranya adalah: 1) PT Pertamina (Persero) Fuel Terminal Cikampek; 2) HIPMI Kabupaten Karawang; 3) Dinas terkait seperti Dinas Kebudayaan dan Dinas Pariwisata Kabupaten Karawang; 4) serta Pemerintah Desa Walahar sebagai pemangku kebijakan di tingkat lokal.

PT Pertamina (Persero) Fuel Terminal Cikampek yang dalam hal ini berperan sebagai mitra utama Yayasan Pesona Walahar Kreatif membuat program pelatihan kapabilitas masyarakat dan perlindungan hukum. Program ini dibuat untuk meningkatkan kemampuan SDM dalam pengelolaan program terutama dalam pembangunan kelompok kawasan wisata dan penerapan CHSE bagi wilayah destinasi wisata dan melakukan perlindungan hukum melalui pembentukan kelompok UMKM menjadi badan hukum Yayasan Pesona Walahar Kreatif. PT Pertamina (Persero) Fuel Terminal Cikampek juga melakukan pembangunan kawasan integrasi. Pembangunan kawasan ini merupakan pembangunan kawasan ekonomi kreatif dengan nama Danau Cinta Eco Resort. Kawasan ini dijadikan pusat promosi dan marketing produk para penerima manfaat dari Yayasan 
Pesona Walahar Kreatif serta dijadikan tempat pelatihan dan workshop. Pembangunan kawasan ini, menggunakan metode kewirausahaan dengan pendekatan model bisnis kanvas sederhana, dengan perencanaan skala kecil dan besar sebagai langkah untuk mempertahankan dan meningkatkan ekonomi para penerima manfaat.

Dalam menjalankan kegiatan pemberdayaan pada UMKM, The Fruters Model bisa dijadikan model pemberdayaan alternatif bagi Yayasan Pesona Walahar Kreatif di Desa Walahar. The Fruters Model (Purnomo, dkk., 2017) merupakan model pemberdayaan masyarakat yang berasaskan technopreneurship, yakni teknologi hasil penelitian dirancang dalam bentuk produk bernilai tambah dan dijadikan penggerak pemberdayaan yang dikolaborasikan dengan para pemangku kepentingan pentahelix yaitu akademisi, bisnis, komunitas, pemerintah, dan media sehingga rangkaian permodelan ini memiliki nilai serta dampak positif yang luas. Menurut Susanti (2018), model ini memetakan kontribusi dan peran para pemangku kepentingan sehingga setiap elemen yang terlibat bekerja sesuai peran yang diambil untuk menyukseskan program dan mewujudkan pemberdayaan yang lebih sinergis. Di bawah ini adalah gambaran dari The Fruters Model yang digagas oleh Purnomo (2014).

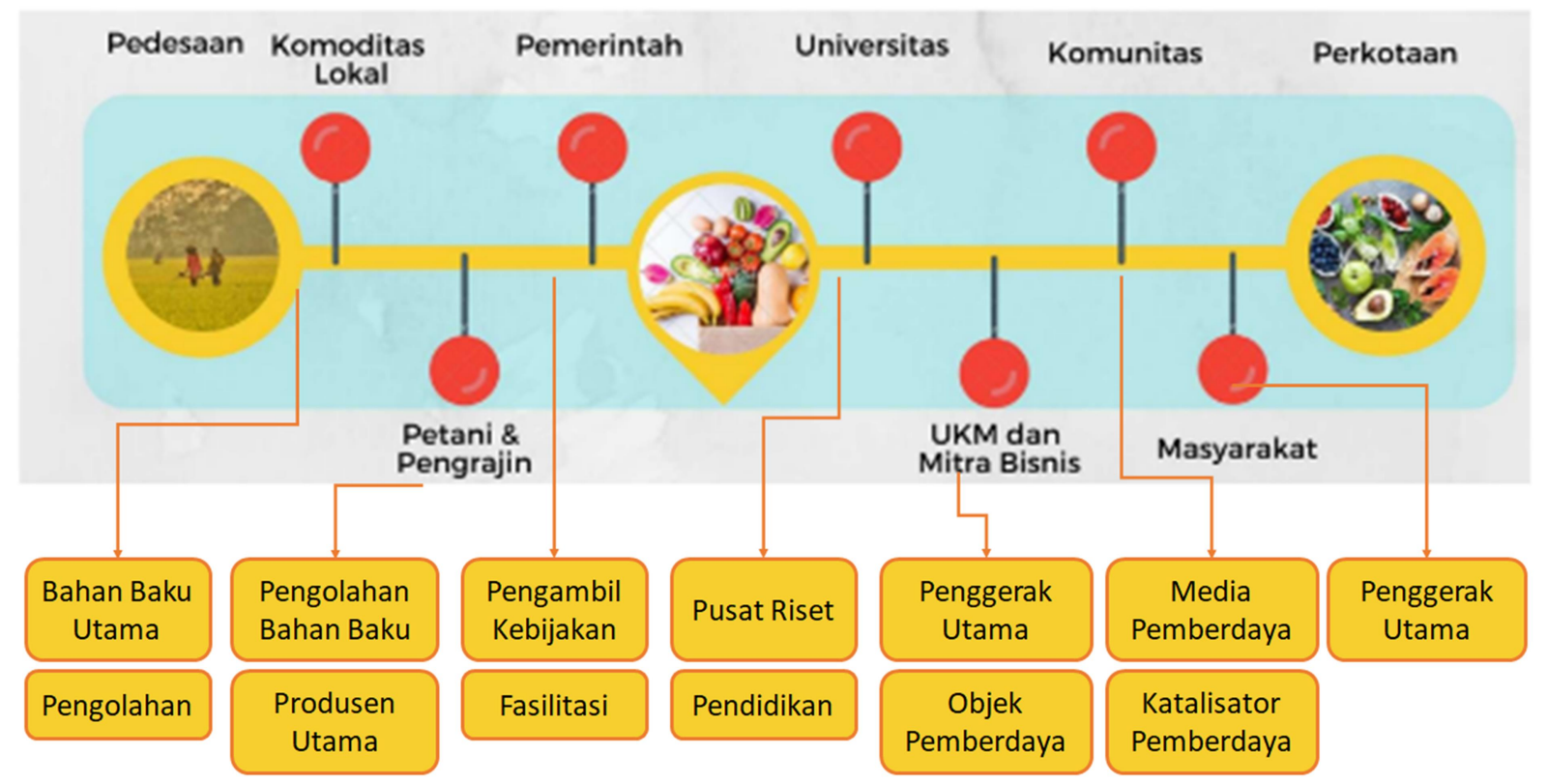

Gambar 1. Program Peningkatan Peran The Fruters Model

Gambar 1 menjelaskan bahwa dalam pelaksanaan pemberdayaan menggunakan The Fruters Model, diperlukan kelengkapan keikutsertaan para pemangku kepentingan guna mensukseskan program unggulan dan mewujudkan pemberdayaan yang sinergis. Pada tingkat lokal, komoditas unggulan lokal dijadikan bahan baku utama dan ditingkatkan peranan aktor yang ada dalam proses pengolahan bahan baku tersebut. Di tingkat produsen 
Pengaruh Inovasi Sosial "Local Business Development" dengan Strategi Business Model Canva (BMC) Terhadap Model Bisnis UMKM Program CSR Pesona Walahar Creative Destinantion Binaan PT. Pertamina (Persero) Fuel Terminal Cikampek

Taufik Ismail, Reza Rinaldy, Mezy Fadhila, Nuril Endi Rahman

dan pengrajin yang berperan sebagai pengolah bahan baku, peranannya perlu ditingkatkan menjadi produsen utama. Program yang perlu dibangun adalah program yang memiliki outcomes mampu menjadikan desa menghasilkan bahan baku utama dan industri pengolahan yang baik. Kemudian bagi pemerintah sebagai pengambil kebijakan, peranannya perlu ditingkatkan sebagai fasilitator pengembangan program. Pihak universitas atau akademisi berperan sebagai pusat riset, peranannya perlu ditingkatkan untuk membumikan pendidikan dan hasil riset kepada masyarakat. Membumikan keilmuan memang menjadi salah satu tantangan tersendiri, namun hal ini perlu dilakukan untuk peningkatan kapasitas dan melakukan pembaruan bisnis model di masyarakat. Sementara itu, para pelaku UMKM dan pelaku ekonomi kreatif akan menjadi penggerak dan objek utama pemberdayaan. Di sisi lain, peran komunitas yang ada di masyarakat dapat dijadikan media pemberdaya dan dapat dijadikan katalisator pemberdayaan melalui ruang-ruang diskusi kolaboratif yang bersifat inklusif bagi seluruh pelaku UMKM dan pelaku ekonomi kreatif. Dan yang terakhir adalah masyarakat yang juga ikut andil besar sebagai penggerak utama. Program lengkap yang dapat dilaksanakan pada tiap lini pemangku kepentingan berdasarkan The Fruters Model adalah sebagai berikut:

1. Program Peningkatan Kualitas Komoditas Unggulan

Program yang dapat dikembangkan untuk peningkatan kualitas komoditas unggulan harus mampu meningkatkan mutu dan kapasitas desa dalam menghasilkan berbagai komoditas unggulan. Program yang dapat dikembangkan seperti pengembangan produk dan pemasaran.

2. Program Peningkatan Kapasitas Petani dan Pengrajin

Peningkatan kapasitas petani dan pengrajin dapat dilakukan dengan diseminasi penelitian, workshop teknologi tepat guna, maupun metode terbaru hasil proses pendidikan yang dilakukan oleh akademisi. Program peningkatan kapasitas ini harus menggunakan pendekatan yang lebih humanis dan sesuai dengan karakter sosial kemasyarakatan para produsen dan pengrajin di Desa Walahar.

3. Program Penguatan Kapabilitas dan Kapasitas Pemerintah

Pemerintah sebagai pengambil kebijakan di masyarakat memerlukan program penguatan kapabilitas dan kapasitas pemerintah sebagai fasilitator. Fasilitator akan berperan sebagai observer kondisi dan keinginan masyarakat. Fasilitator juga berperan sebagai penerjemah berbagai kebijakan ke masyarakat. Sehingga pemerintah dapat melihat langsung apakah dampak kebijakan yang ditetapkan sesuai dengan kondisi dan kebutuhan masyarakat. 


\section{Program Knowledge Sharing Universitas}

Pelibatan peran universitas dalam program knowledge sharing dapat mengakselerasi objek pemberdayaan dalam meningkatkan metodologi, teknologi, maupun peningkatan kapasitas. Para akademisi juga dapat melakukan penelitian yang sesuai dengan kondisi masyarakat di Desa Walahar.

\section{Program Akselerasi UMKM dan Mitra Bisnis}

Program inkubasi dapat dilakukan untuk akselerasi UMKM dan para pelaku ekonomi kreatif yang ada di Desa Walahar. Outcomes program inkubasi ini adalah agar para UMKM dan para pelaku ekonomi kreatif di Desa Walahar mampu scale-up bisnisnya masing-masing dan siap mendapat suntikan dana dari investor.

6. Program Pemberdayaan Komunitas dan Masyarakat

Program mentoring dapat dilaksanakan untuk pemberdayaan di level komunitas dan masyarakat yang diatur dalam jangka waktu tertentu sehingga tidak hanya menjadi program jangka pendek. Pendampingan atau mentoring ini bertujuan untuk menjadikan komunitas dan masyarakat lebih siap mengaplikasikan keilmuan dan program pemberdayaan.

7. Program Pemasaran ke Konsumen dan Perkotaan

Program pemasaran dapat dilakukan dengan menggunakan pemetaan segmentasi konsumen yang kemudian dapat dijadikan acuan pengembangan produk yang sesuai dengan kebutuhan pasar. Metode penyampaiannya dapat menggunakan marketing funnel melalui media daring atau luring sesuai dengan posisi segmentasi konsumen pada level marketing funnel.

PT Pertamina (Persero) Fuel Terminal Cikampek sebelumnya telah melakukan pemetaan aktor atau pemetaan pemangku kepentingan yang tertuang dalam Laporan Pemetaan Sosial 2020. Pemetaan ini dilaksanakan agar dapat dijadikan alat untuk mencari informasi, mendeskripsikan, menganalisis, serta memprediksi kondisi sosial masyarakat di Desa Walahar. Harapannya para inisiator dan/atau pelaksana program di masa yang akan datang dapat memanfaatkan hasil pemetaan untuk merancang program CSR yang lebih humanis, sesuai dengan kondisi dan kebutuhan masyarakat Desa Walahar, serta dapat dipertanggungjawabkan sesuai dengan acuan proper dari Kementerian Lingkungan Hidup (KLH). 
Pengaruh Inovasi Sosial "Local Business Development" dengan Strategi Business Model Canva (BMC) Terhadap Model Bisnis UMKM Program CSR Pesona Walahar Creative Destinantion Binaan PT. Pertamina (Persero) Fuel Terminal Cikampek

Taufik Ismail, Reza Rinaldy, Mezy Fadhila, Nuril Endi Rahman

\section{KESIMPULAN DAN SARAN}

Inovasi sosial yang dilakukan oleh tim CSR PT Pertamina (Persero) Fuel Terminal Cikampek dengan titik ungkit pemberdayaan melalui Yayasan Pesona Walahar Kreatif memunculkan sifat kolaboratif dan saling bahu membahu di kalangan para penerima manfaat di Desa Walahar untuk terus bertahan menjalankan usaha di masa pandemi Covid19. Promosi dilakukan bersama-sama melalui media sosial dan forum bisnis dan dijadikan media yang ampuh untuk menjaga hubungan dengan para pelanggan. Selain itu, UMKM dan para pelaku ekonomi kreatif menjalin hubungan yang baik dengan para pemangku kebijakan untuk menjaga eksistensi mereka. Pemangku kebijakan yang paling aktif membantu penerima manfaat dari Yayasan Pesona Walahar Kreatif adalah dari PT Pertamina (Persero) Fuel Terminal Cikampek yang memberikan bantuan program dan sarana prasarana bagi mereka. Ke depannya, Yayasan Pesona Walahar Kreatif dan para penerima manfaatnya perlu membangun kerjasama dengan para pemangku kepentingan untuk akselerasi kebaruan ilmu pengetahuan dan model bisnis, pengembangan strategi pemasaran dan produksi berkelanjutan, serta akselerasi pemasaran yang dilakukan secara paralel agar tidak tergerus di era disrupsi dan pandemi Covid-19.

\section{UCAPAN TERIMAKASIH}

Rasa terimakasih kami ucapkan kepada seluruh stakeholder di kawasan Desa Walahar. Rasa terimakasih juga diucapkan kepada PT. Pertamina Fuel Terminal Cikampek, sebagai stakeholder yang terlibat dalam pembinaan UMKM melalui program CSR di kawasan Walahar.

\section{DAFTAR PUSTAKA}

PT. Pertamina (Persero) Fuel Terminal Cikampek. (2020). Laporan Pemetaan Sosial 2020. Purnomo, D., dan Kurniawan, K. I. A. (2017). Sociopreneur Millenial. Bandung: Bitread Publishing.

Susanti, S., Purnomo, D., Gunawan, W., dan Sari, D. (2018). Komunikasi Pemasaran Produk Komoditas Lokal Berbasis Komunitas Melalui Penggunaan Media (Studi Kasus FruitsUp, UMKM di Jatinangor). Jurnal Sosiohumaniora. Vol. 20, No. 3, Nopember 2018: 277-281.

Purnomo, Dwi, 2014. The Fruters Model: Model Pemberdayaan Berbasis Technopreneurship. Anugerah Prakarsa Jawa Barat 2014. 